\title{
Psicologia, Democracia e Laicidade em Tempos de Fundamentalismo Religioso no Brasil
}

\author{
Tatiana Lionço \\ Universidade de Brasília, DF, Brasil.
}

\begin{abstract}
Resumo: A laicidade é um princípio fundamental para a garantia da ética democrática, pois promove o reconhecimento e proteção da diversidade social, moral, cultural e religiosa de uma sociedade. As liberdades individuais são direitos modernos relativos à dissociação entre poder estatal e dogma religioso, de modo a garantir liberdade de consciência e de expressão, fundamentais à dignidade humana. A Psicologia afirmou historicamente compromisso com a ética democrática e com os direitos humanos, sendo um importante ator político e social pois participa do processo de redemocratização brasileiro por meio de sua inserção em diversas políticas públicas de garantia de direitos sociais. Diante da incidência do discurso religioso de viés fundamentalista e antidemocrático no atual cenário político brasileiro, a Psicologia se encontra na posição de alvo de ofensivas fundamentalistas contemporâneas contra normativas éticas da profissão, em tempo em que também sofre tensionamentos internos na lógica da reivindicação de uma "Psicologia cristã". Em meio a este cenário complexo, o sistema conselhos de Psicologia tem produzido marcos de referência para a defesa da laicidade e recusa de fundamentalismos, sendo atualmente um ator estratégico na defesa da democracia brasileira.
\end{abstract}

Palavras-chave: Laicidade, Fundamentalismo Religioso, Ética Democrática, Psicologia Política.

\section{Psychology, Democracy and Laicity in Times of Religious Fundamentalism in Brazil}

\begin{abstract}
Laicity is a fundamental principle for the guarantee of democratic ethics, since it promotes the recognition and protection of the social, moral, cultural and religious diversity of a society. Individual freedoms are modern rights concerning the dissociation between state power and religious dogma, in order to guarantee freedom of conscience and expression, fundamental to human dignity. Psychology has historically affirmed a commitment to democratic ethics and human rights, being an important political and social actor because it participates in the Brazilian redemocratization process through its insertion in several public policies guaranteeing social rights. Confronted by the incidence of religious discourse of fundamentalist and antidemocratic bias in the current Brazilian political scene, Psychology is a target of contemporary fundamentalist offensives against the ethical norms of the profession, and it also suffers internal tensions in the logic of claiming a "Christian psychology ". Challenged by this complex scenario, the system of Psychology Councils has produced benchmarks for the defense of secularism and the rejection of fundamentalisms, and is currently a strategic actor in the defense of Brazilian democracy.
\end{abstract}

Keywords: Religious Fundamentalism, Laicity, Democracy, Political Psychology. 


\title{
Psicología, Democracia y Laicidad en Tiempos de Fundamentalismo Religioso en Brasil
}

\begin{abstract}
Resumen: La laicidad es un principio fundamental para la garantía de la ética democrática, pues promueve el reconocimiento y protección de la diversidad social, moral, cultural y religiosa de una sociedad. Las libertades individuales son derechos modernos relativos a la disociación entre poder estatal y dogma religioso, para garantizar la libertad de conciencia y de expresión, fundamentales a la dignidad humana. La Psicología afirmó históricamente compromiso con la ética democrática y con los derechos humanos, siendo un importante actor político y social pues participa del proceso de redemocratización brasileño por medio de su inserción en diversas políticas públicas de garantía de derechos sociales. Ante la incidencia del discurso religioso de sesgo fundamentalista y antidemocrático en el actual escenario político brasileño, la Psicología es blanco de ofensivas fundamentalistas contemporáneas contra normativas éticas de la profesión, al tiempo que también sufre tensiones internas en la lógica de la reivindicación de una "Psicología cristiana". Ante este escenario complejo, el sistema de Consejos de Psicología ha producido marcos de referencia para la defensa de la laicidad y rechazo de fundamentalismos, siendo actualmente un actor estratégico en la defensa de la democracia brasileña.
\end{abstract}

Palabras clave: Laicidad, Fundamentalismo Religioso, Ética Democrática, Psicología Política.

\section{Introdução}

O processo de secularização característico da Modernidade, em consonância com a laicização das repúblicas democráticas, trouxe a emergência de novos direitos decorrentes da ascensão do liberalismo, entre os quais a liberdade de consciência e de expressão. A proteção às liberdades individuais e o princípio democrático e consonante aos direitos humanos da inviolabilidade da dignidade humana implica, necessariamente, o direito à livre expressão da consciência e das crenças. Os sujeitos na era secular passam a dispor da prerrogativa de enunciar, em seus próprios termos, o sentido que conferem a si próprios, à vida social e às proposições para a vida em coletividade (Nussbaum, 2008; Schlegel, 2009).

Uma das forças de oposição contemporânea aos ideais democráticos é o fundamentalismo religioso, que alega que os ideais iluministas e a consequente secularização da sociedade decorreram em prejuízos morais e afrontas a preceitos de fé que organizavam a vida social. Entre os prejuízos elencados, afirma-se a necessidade de defender valores tradicionais relativos à família heteronormativa e monogâmica presumida sagrada, à concepção do papel social de homens e mulheres e à suposta decência das práticas sexuais restrita a ideais familistas de procriação. Neste sen- tido, o fundamentalismo religioso em suas variadas nuances contingenciais encontra como eixo estruturante a ofensiva contra direitos adquiridos pela luta política das mulheres e de minorias sexuais tais como homossexuais, travestis, transexuais e profissionais do sexo (Boff, 2002; Santos, 2013a).

O fundamentalismo religioso é uma ofensiva contemporânea a preceitos da modernidade. Recusa princípios democráticos seculares em uma era de instabilidade e dispersão das representações, reivindicando o retorno de tradições como preceitos basilares da vida social. O fundamentalismo religioso é uma reação às novas contingências históricas e políticas que prevêem o reconhecimento da diversidade moral, cultural e das possibilidades diversas de subjetivação da humanidade. "Os fundamentalismos acreditam que estão combatendo forças que ameaçam seus valores mais sagrados" (Armstrong, 2009, p. 18). É um movimento que se consolida no século XX contra a hegemonia secular e uma "forma de reconduzir Deus ao campo da política, do qual fora banido" (Armstrong, 2009, p. 491).

No contexto brasileiro, a incidência do discurso religioso de viés fundamentalista na agenda política tem sido debatida por vários autores (Cunha, Lopes e Lui, 2017; Lionço, 2015; Natividade, 2016; Natividade, 
\& Oliveira, 2013; Vital, \& Lopes, 2013), com ênfase para o caráter antidemocrático da incidência dos discursos religiosos na política, e mais especificamente decorrendo em retrocessos na agenda de direitos humanos.

Neste contexto histórico e político, vale considerar a relação entre a laicidade, o fundamentalismo religioso e a Psicologia. Considera-se aqui a Psicologia como ator político no atual cenário contemporâneo para refletir sobre sua posição diante da laicidade bem como diante da incidência do fundamentalismo religioso como ofensiva contemporânea antidemocrática. O objetivo do artigo é evidenciar as contradições nas relações estabelecidas pela Psicologia com a defesa da laicidade e também com o fundamentalismo religioso. Para tanto será considerada a Psicologia em sua dimensão de profissão regulamentada e referida a um sistema conselhos que tem como atribuição a fiscalização e a orientação do exercício profissional. A Psicologia como ciência é reconhecida em sua diversidade epistemológica, cabendo considerações críticas sobre o processo histórico de revisão de pressupostos éticos e epistemológicos das teorias psicológicas para o cumprimento do compromisso social da Psicologia com a ética democrática e a defesa e proteção dos direitos humanos e sociais.

Vale ressaltar que aqui se está contrapondo a um modelo de Psicologia que serviu como ferramenta de normalização em contextos de autoritarismo e violação de direitos tais como durante a ditadura civil militar brasileira (Scarparo, Torres, \& Ecker, 2014). Espera-se, portanto, contribuir para a sedimentação de uma Psicologia crítica e aliada à defesa da democracia brasileira diante de novo contexto histórico e político de ascensão conservadora e de abuso de autoridade na política nacional. Para tanto, serão realizadas reflexões sobre a atual posição da Psicologia como profissão comprometida com o marco constitucional democrático e sua participação na defesa da laicidade, por meio da consideração dos marcos normativos e posicionamentos institucionais dos conselhos de Psicologia.

Este estudo teve como eixo condutor a participação no Grupo de Trabalho de Laicidade e Psicologia vinculado à Assembleia de Políticas, da Administração e Finanças do Sistema Conselhos de Psicologia (APAF) entre dezembro de 2013 e dezembro de 2016. Os caminhos de teorização sobre laicidade, democracia e Psicologia sistematizados no presente artigo refletem o esforço em produzir conhecimento sobre as relações entre Psicologia e laicidade ao longo deste período. O levantamento preliminar de referências bibliográficas sobre o tema foi atualizado anualmente por meio das plataformas SciELO e Periódicos Eletrônicos em Psicologia, não existindo nenhum artigo sobre laicidade e Psicologia indexado nas referidas bases de dados até a finalização da participação no grupo de trabalho. Apenas em 2017 surge o primeiro artigo científico a partir do cruzamento das palavras-chave "psicologia" e "laicidade", localizado por meio da plataforma SciELO. O cruzamento dos termos de busca "psicologia" e "religião", "religiosidade" e "espiritualidade", no entanto, permitiram a localização de artigos acadêmicos que discutem a relação entre saúde mental e religiosidade e/ou espiritualidade, a relação entre religiosidade e subjetividade, percepções de acadêmicos de Psicologia sobre o fenômeno religioso e a história da Psicologia no Brasil, temas afeitos ao campo da Psicologia da Religião, não sendo coincidente com o recorte do presente estudo.

A insipiência da produção de conhecimento sobre as relações entre laicidade e Psicologia moveu o atual esforço de teorização e pesquisa. O desafio enfrentado foi o da sistematização de um discurso teórico que permitisse articular a laicidade à Psicologia. Partindo de uma matriz interdisciplinar de referências, buscou-se articular a emergência histórica da laicidade a princípios expressos no Código de Ética Profissional do Psicólogo, a saber, a defesa da dignidade, da liberdade de consciência e/ou de crença, a defesa dos direitos humanos e o compromisso com a ética democrática. Tais reflexões se apoiaram em narrativas do campo da filosofia política e de análises sociológicas sobre o fenômeno contemporâneo do fundamentalismo religioso no Brasil, sem a pretensão de esgotar o levantamento e a revisão de bibliografia de referência.

A fim de apresentar a complexidade da imersão da Psicologia no embate entre a defesa da laicidade e a incidência do fundamentalismo religioso no contexto político brasileiro contemporâneo, serão realizadas a seguir reflexões teóricas. Primeiramente, será discutida a emergência da laicidade na Modernidade e sua relação com a ética democrática, considerando a emergência do direito à dignidade humana fundamental para a consideração contemporânea dos direitos humanos em sociedades marcadas pela diversidade. Em seguida, serão discutidas teoricamente as relações entre Psicologia, democracia e direitos humanos. As proposi- 
ções legislativas e polêmicas em torno da Resolução CFP n ${ }^{\circ}$ 01/1999 (Conselho Federal de Psicologia, 1999) serão então analisadas como amostra de conveniência para a reflexão sobre as relações entre Psicologia, laicidade e fundamentalismo religioso.

\section{Laicidade, democracia e dignidade humana}

A laicidade é um princípio de organização das práticas do Estado e instituições que interfere na organização social, defendendo incondicionalmente a liberdade de consciência e a liberdade de expressão (Nussbaum, 2008), ressalvados os interditos penais. O ponto cego da democracia laica é a possibilidade de proteção da existência de discursos avessos à própria laicidade e à ética democrática. No interior das democracias laicas também podem surgir expressões de crenças de que a lógica democrática e laica deve ser alterada, opondo-se à democracia e à laicidade. Este é o caso do fundamentalismo religioso (Schlegel, 2009).

O princípio da laicidade emerge historicamente com a secularização e com o surgimento dos direitos relativos à individualidade no liberalismo, tais como liberdade de consciência, liberdade de expressão e consequentemente liberdade religiosa, política e de associação (Nussbaum, 2008; Schlegel, 2009). A secularização é um processo característico da transição para a era moderna em que a sociedade deixa de se pautar em verdades unívocas transcendentais para considerar a multiplicidade discursiva como fundamento das práticas sociais. Seu desdobramento, nas práticas de governo, é a emergência do princípio da laicidade que se funda no reconhecimento da diversidade moral como fato social. O Estado laico na era secular, portanto, deixa de fundar suas práticas, atos normativos e retóricas orientadoras à verdade transcendental da religião (Armstrong, 2009; Schlegel, 2009), organizando suas práticas na lógica da proteção da diversidade social.

Durante longos períodos históricos, os Estados, a autoridade de seus governantes e suas formas de governar populações tinham como fundamento a verdade religiosa, não cabendo o dissenso ou oposição sob pena de exclusão ou mesmo extermínio. As guerras entre os povos pautadas na religiosidade se basearam, e ainda se baseiam, na afirmação de verdades que não se propõe objeto de questionamento ou crítica em processos de negociação entre grupos sociais distintos. Muitos extermínios foram desencadeados sem que houvesse processo de diálogo e considera- ção mútua de interesses e necessidades. Ganhar uma guerra significava então adquirir o direito de impor a uma dada região e sua população de referência um conjunto de crenças e práticas sociais não passíveis de questionamento (Armstrong, 2016).

Isso mudou na transição para a Modernidade, sendo uma das características da emergência da era moderna o surgimento de outra forma de produzir conhecimento válido. A racionalidade científica propõe outra lógica de validade para os discursos, não consentindo mais com o absolutismo da verdade transcendental. Na Modernidade secular, portanto, os discursos válidos passaram a se multiplicar, não cabendo mais a destituição do dissenso com base na presunção de inquestionabilidade de um discurso que estivesse imune ao escrutínio da avaliação pública e coletiva, a partir de variados pontos de vista e paradigmas diversos (Schwartzman, 2008).

Isso muda a forma como o Estado passa a organizar suas práticas, tendo como fundamento a produção discursiva que o próprio debate público legitima. Todo e qualquer discurso se torna assim passível de questionamento, incluindo a retórica religiosa. O processo incessante de questionar as próprias normas é característico da sociedade democrática. Para Schlegel (2009), a democracia moderna significa o fim do regime teológico-político e do poder de autoridade sagrada e surgimento do poder de base popular. Com a emergência da laicidade como operador das práticas de dissociação entre o poder do Estado e poder religioso, o dissenso passa a ser incontornável a partir da emergência histórica da liberdade de consciência e de expressão.

Para que este processo de revisão permanente ocorra, as pessoas e grupos sociais devem poder discordar. Se não há possibilidade de dissenso também já não há possibilidade de crítica e revisão de normas. Emerge então historicamente o direito à oposição, sendo o direito ao protesto uma conquista constitucional fundamental para a manutenção da democracia. Por meio do debate público e do acolhimento de proposições discordantes se busca qualificar os processos por meio dos quais o próprio conjunto da sociedade delibera o modo de regular a vida social. A justiça social não é um princípio autoevidente: é por meio dos processos de participação social e de multiplicação das vozes dissonantes que podemos avaliar a eficácia das práticas de governo e buscar alterá-las por meio da crítica. Para alcançar modos mais justos 
de organização das práticas de governo e de organização da vida em sociedade devemos levar em consideração a multiplicidade de interesses e o respeito às liberdades de outrem (Sen, 2011).

Na Modernidade surge historicamente o discurso razoável - e, portanto, sempre passível de questionamento - como novo fundamento de organização das instituições de poder. A razão do Estado é o que orienta a agência dos governos e instituições na proposição, implementação e avaliação de estratégias práticas de garantia de direitos para a população.

A laicidade é um dispositivo de proteção da diferença, sendo, assim, um princípio de promoção da valorização da diversidade social. A democracia pode ser entendida como o compromisso com o reconhecimento, consideração e respeito às diferenças entre indivíduos e grupos sociais. Esta diferença pode remeter a diversos marcadores sociais, entre os quais a condição étnico-racial, de sexo, de religiosidade, de cultura, de regionalidade, de orientação sexual, de identidade de gênero etc. É importante salientar que, na origem da emergência histórica da laicidade como princípio de governabilidade que protegeria os direitos individuais à liberdade de consciência e de expressão, os oponentes de tais propostas alegavam, no século XVIII, que a perseguição moral e religiosa poderia se justificar eticamente diante da necessidade de defender a ordem civil (Nussbaum, 2008). Da mesma forma, na contemporaneidade brasileira os discursos conservadores alegam que o processo de democratização decorreria em risco social, requerendo coibição de direitos políticos e sociais (Demier, 2016; Lionço, 2015) e de políticas de promoção da equidade tais como a educação democrática comprometida com o debate sobre gênero e sexualidade nas escolas (Barbara, Cunha, \& Bicalho, 2017; Frigotto, 2017).

É neste sentido que se pode associar o fundamentalismo religioso ao nacionalismo (Nussbaum, 2012; Schlegel, 2009). O fundamentalismo religioso não necessariamente se associa ao nacionalismo, mas, considerando o fundamentalismo cristão e a emergência da nova direita na América do Norte e mais recentemente no Brasil contemporâneo - ambos Estados marcados por ampla diversidade étnica e cultural -, o argumento da moralização da política associado à lógica salvacionista da nação por meio de valores religiosos tem sido uma das estratégias de tomada de poder que deve ser considerada. O fundamentalismo religioso é expressão de forças políticas conservadoras extremistas que uti- lizam as polarizações morais para fins de demarcação de nichos eleitorais. Primando por projetos políticos de enfraquecimento do Estado de direitos, legitimam a exclusão e/ou precarização de direitos a determinados segmentos populacionais em prol da manutenção de privilégios para grupos em situação de poder hegemônico em um contexto social desigual.

Para Facchini e Sívori (2017),

Organizados como bancada no Congresso Nacional, na sua atuação pública, parte importante desses parlamentares evoca uma visão idealizada de unidade do "povo de Deus" como suposta maioria nacional para agitar ansiedades morais com um relato apocalíptico no qual os direitos e políticas para as mulheres e LGBT, além de cercear a liberdade religiosa, ameaçariam a integridade moral das crianças e da família brasileira (s.p.).

Está em curso no Brasil a proliferação de polêmicas que levam ao pânico moral associado à agenda de direitos humanos e especialmente dos direitos sexuais e reprodutivos (Natividade, \& Oliveira, 2009; Vital, \& Lopes, 2013), tendendo à criminalização dos movimentos sociais e incitação do ódio contra ativistas feministas e LGBT (Lionço, 2015). Nussbaum (2008) sugere que a dignidade como direito emerge da premissa moderna de que todo ser humano tem faculdade moral e espiritual, sendo um direito associado aos direitos individuais à livre consciência e à livre expressão. Com a ascensão do liberalismo na era secular não caberia mais a tomada de parâmetro moral unívoco a partir do qual sujeitos passariam a ser medidos ou avaliados moralmente, mas cada pessoa passaria a dispor do direito à dignidade ao enunciar em seus próprios termos morais e culturais o sentido que conferiria a si mesmo e à vida social.

Todas as pessoas em uma dada sociedade, ainda que vinculadas a diferentes religiões e tradições culturais, podem compartilhar perguntas sobre o sentido da vida. Não é legítima a desqualificação a determinados grupos que, não estando necessariamente vinculados a determinada religião, também buscam em seus pertencimentos comunitários responder questões sobre o que seria o justo e sobre como agir da melhor forma na vida e nas relações sociais. Estas são questões que as religiões se colocam, assim como outras instituições da sociedade secular voltadas para o cumprimento da justiça e das boas condições de 
vida. $\mathrm{O}$ direito à dignidade é fundamento primeiro da secularização e emergência da laicidade, expressa materialmente no direito consequente da liberdade de consciência e da liberdade de expressão.

A laicidade como dispositivo de proteção da liberdade de consciência e de expressão surge garantindo que numa dada sociedade as pessoas não precisam pensar e ser iguais. A Declaração Universal dos Direitos Humanos foi uma tentativa histórica de afirmação da inviolabilidade do direito à dignidade humana, após uma Segunda Guerra Mundial que se desdobrou no esforço de um conjunto de nações à oposição ao projeto político de extermínio. O horror ao extermínio da diferença foi o que orientou a proposição histórica da Declaração Universal dos Direitos Humanos.

$\mathrm{O}$ direito à dignidade humana, apesar de parecer um conceito autoevidente e básico, se mostra extremamente complexo. É um direito afirmado após longos períodos em que nem sempre se concebeu todas as pessoas como humanas. A era das trevas ou Idade Média foi um momento histórico de legitimação de intensa violência genocida por meio do processo inquisitorial. Operacionalizada por meio de tribunais de julgamento da heresia com base em verdades transcendentais inquestionáveis, não se dispunha do direito a ser reconhecido como sujeito que pudesse dizer em seus próprios termos quem é e o sentido do que faz. Muitas pessoas foram não apenas mortas, mas agredidas com requintes de crueldade, impondo uma marca bastante dramática de violência a períodos históricos em que a verdade religiosa cerceou a liberdade de crença das pessoas. Na mesma forma, o nacionalismo autoritário na forma de regime de governo ditatorial ecoa tais mecanismos sombrios em tempos históricos modernos, tais como os vividos pela sociedade brasileira durante a ditadura civil-militar que decorreu em perseguições políticas, detenções arbitrárias e práticas de crueldade na forma de tortura, mesmo em uma era secular.

$\mathrm{O}$ direito à dignidade implica que toda pessoa possa dizer, em seus próprios termos, quem entende que é e como entende que leva a vida. Por isso, devemos recusar discursos de determinados grupos sociais que se referem a outros grupos sociais como não humanos ou menos humanos, garantindo a palavra a esses próprios grupos para que digam por si mesmos como se reconhecem e como entendem o modo de levar a vida e a ideia do justo. Tanto mais justa será a justiça quanto mais e melhor atender às diferenças entre as pessoas e grupos sociais em uma vida social compartilhada. Cada grupo pode ajudar a todo o conjunto da sociedade entender o que haveria de ser justo. Tanto mais justa será uma norma quanto mais estiver atenta às diferenças que integram o conjunto da sociedade. Se a norma for pensada a partir do que apenas uma parte da sociedade pensa, esta norma não será justa para outros grupos sociais que não tiveram suas próprias representações consideradas. É por isso que as leis e outras normas não devem impor exatamente como as pessoas devem levar a vida, mas apresentar interditos sobre o que não seria legítimo fazer por acarretar danos a outrem, reservando às pessoas e grupos liberdade no modo como conduzem as próprias vidas em responsabilidade junto ao conjunto sempre mais amplo da sociedade (Sen, 2011).

\section{Psicologia, direitos humanos, democracia}

A Psicologia, tendo surgido historicamente como ciência, também desde sua origem se coloca na posição laica de ser passível de questionamento em seus discursos e práticas, de modo que, ao longo de pouco mais de um século de existência, a própria Psicologia em suas variadas vertentes epistemológicas vem se debruçando sobre a própria história para transformar seus discursos e práticas a partir de críticas internas e externas a ela mesma. Este é também o exercício próprio das ciências, pois a ciência pretende legitimar discursos válidos e não discursos pretensamente verdadeiros e inquestionáveis. O método próprio de validação do conhecimento científico é colocar em dúvida por meio do acolhimento e consideração de proposições argumentativas contrárias, visando a ética da justificação como horizonte de sua validade num dado momento histórico e contingencial.

Rose (2011) propõe o revisionismo histórico da Psicologia em sua intencionalidade tecnológica, ou seja, considera a Psicologia como campo de conhecimento que agencia práticas e, portanto, promove determinadas formas de representar a vida social, a humanidade e um dado projeto de sociedade. É necessário recuperar as críticas sobre o caráter normalizador da ciência psicológica, bem como da tecnologia individualizante que diversos saberes psicológicos agenciaram historicamente, dificultando a reflexão crítica sobre condicionantes sociais, econômicos, históricos e culturais dos processos de subjetivação e de promoção/violação de direitos por 
meio das práticas psicológicas. Parte-se aqui da premissa de que a Psicologia pode afirmar seu compromisso com um projeto democrático de sociedade, por meio da consideração crítica do viés individualizante rumo ao reconhecimento e consideração dos fatores sociais, históricos e políticos em diversos contextos de desenvolvimento humano e de agenciamento de subjetividades e práticas institucionais.

Considerar o princípio da laicidade na Psicologia remete ao nosso desafio ético de respeito e proteção às diferenças entre sujeitos e grupos sociais. Por mais que determinadas diferenças subjetivas e sociais se afastem das moralidades hegemônicas em uma dada sociedade, ainda assim integram uma lógica abrangente de pertencimento social. Rorty (2010) nos provoca a pensar sobre o necessário alargamento do círculo que delineia uma dada representação de coletividade, de modo a abranger tanto quanto possível o dissenso e a diferença insuperável entre indivíduos e grupos sociais. Faz-se necessário afirmar o caráter datado do compromisso da Psicologia com os direitos humanos, sendo no Brasil decorrente sobretudo do alinhamento entre os princípios do Código de Ética Profissional do Psicólogo ao marco constitucional de redemocratização (CFP, 2005).

A reflexão sobre direitos humanos implica necessariamente a consideração sobre direitos sociais, econômicos e políticos (Santos, 2013b; Sen, 2010), caso contrário corre o risco de não decorrer em garantia material de boas condições de vida para as pessoas. É neste sentido que Gesser (2013) propõe pensar o desafio contemporâneo da Psicologia pós compromisso com a constituição democrática e com os direitos humanos tais como expressos no código de ética profissional e outras normativas de não discriminação. Fundamentalmente a regulamentação da profissão implica na adesão da categoria profissional a marcos regulatórios estatais, o que se desdobrou na construção, por exemplo, de amplos esforços da Psicologia na proposição de marcos éticos e técnicos para o exercício profissional em contextos de políticas públicas, com especial ênfase para a criação em 2006 do Centro de Referência em Psicologia e Políticas Públicas (Crepop) ${ }^{1}$, que tem desenvolvido marcos de referência técnica para a atuação profissional em variadas estratégias de garantia de direitos humanos e sociais por meio de políticas públicas nas quais profissionais de Psicologia se inserem. Em linhas gerais, a proposta de Gesser (2013) é a de que a Psicologia precisa consolidar o revisionismo histórico sobre sua identidade profissional e seus discursos teóricos na lógica do enfrentamento ao essencialismo de padrões normativos que legitimam opressões contra determinados indivíduos e/ou grupos sociais, garantindo-lhes direito à participação e proposição de caminhos de cuidado de acordo com suas reais necessidades e demandas.

Vale destacar dois marcos normativos que revelam a direção revisionista da Psicologia em compromissos historicamente datados contra formas de opressão passíveis de agenciamento pelos próprios discursos e práticas psicológicas. A Resolução CFP $\mathrm{n}^{\circ}$ 01/1999 (CFP, 1999) veda a patologização e tratamentos de reversão da orientação sexual, bem como a Resolução CFP n ${ }^{\circ}$ 018/2002 (CFP, 2002), que correlativamente afirma a proibição do racismo no exercício profissional, incluindo práticas de conivência com a veiculação de representações de patologização e inferiorização de pessoas negras, suas tradições e práticas culturais e/ou religiosas. Quando alguém é desumanizado ou desqualificado em sua humanidade, seja em função da orientação sexual ou de expressão da fé, tais como homossexuais e adeptos de religiões de matriz africanas, se está destituindo estas pessoas de dignidade por meio de desumanização e de atribuição de desvalor.

Outro marco relevante foi a proposição de Código de Ética Profissional alinhado ao compromisso da Psicologia com um Estado democrático de direitos sociais e afirmando o compromisso com direitos humanos (CFP, 2005). Compromisso com a democracia e com os direitos humanos, implicando respeito à autonomia das pessoas, a proteção à inviolabilidade da dignidade de pessoa humana, à consideração crítica do contexto sócio-histórico e institucional no qual as práticas psicológicas se inserem, à não discriminação e ao veto ao uso do exercício profissional para "induzir a convicções políticas, filosóficas, morais, ideológicas, religiosas, de orientação sexual ou a qualquer tipo de preconceito" (CFP, 2005).

Rosato (2011) nos ajuda a refletir sobre a conivência histórica da Psicologia com interesses hegemônicos e, portanto, avessos à lógica democrática e de garantia dos direitos humanos e sociais, ao explicitar que nas

\footnotetext{
${ }^{1}$ Diversos materiais de referência têm sido desenvolvidos pelo Crepop e podem ser acessados por meio de sítio específico: http://crepop.pol.org.br/novo/cat/publicacoes/referencias-tecnicas. Tais esforços denotam o compromisso concreto do sistema conselhos de Psicologia com a proposição de serviços psicológicos voltados para a garantia de direitos sociais.
} 
próprias legislações de regulamentação da profissão (em 1962) e regulamentação da formação de habilitação para o título de psicólogo (em 1964), estavam explicitados os objetivos de adaptação e de adequação de indivíduos a diversos contextos institucionais, como educação e mercado de trabalho, reservando também à clínica psicoterapêutica intencionalidade normalizadora e portanto cerceadora do reconhecimento da diversidade subjetiva, moral e cultural. Para Rosato (2011),

a partir da (re) democratização do país, o campo psicológico se ampliou e houve uma ruptura com o que inicialmente foi a proposta da profissão. Já não era mais possível manter uma Psicologia individualizante, descontextualizada e a-histórica. Esse momento político vivenciado no país apresenta-se como momento de ruptura para a Psicologia, ou pelo menos, permite à profissão o começo de uma longa e fértil revisão de suas propostas de intervenção. Pode-se dizer, inclusive, que esse novo contexto reforçou a necessidade de uma avaliação da profissão e seus objetivos, enfim, de sua função pública perante a sociedade brasileira (p. 16).

Os marcos éticos e técnicos da profissão resguardam a autonomia de profissionais de Psicologia no uso de diferentes bases teóricas e técnicas, orientando a profissão a partir de posicionamentos que abrangem um conjunto amplo de discursos e práticas em Psicologia. Requer, no entanto, a consideração do caráter datado de vários discursos teóricos da Psicologia, posto que, em momentos históricos anteriores ao compromisso com a ética democrática e com os direitos humanos, a Psicologia produziu narrativas coniventes com a naturalização das desigualdades sociais e atribuição de anormalidade a grupos sociais historicamente estigmatizados e/ou minoritários diante de um contexto de hegemonia moral.

Reconhecendo que a Psicologia, seus discursos e práticas podem tanto agenciar tecnologias de promoção ou de violação de direitos humanos, torna-se relevante considerar a importância da construção de marcos normativos de referência que afirmem o compromisso em construir "uma sociedade menos injusta e que tenha como princípio norteador o respeito à dignidade humana" (Rosato, 2011, p. 26).

\section{Método}

Esta é uma pesquisa exploratória qualitativa, organizada em torno de uma amostra de conveniência. Optou-se pela realização de uma análise qualitativa de documentos públicos que aproximam a Psicologia do fenômeno contemporâneo do fundamentalismo religioso e/ou da defesa da laicidade do Estado. Foi realizada análise de documentos na lógica da metodologia de pesquisa qualitativa da Teoria Fundamentada (Strauss, \& Corbin, 2008), que tem como horizonte a produção de teorização sobre determinado objeto fundamentada em evidências empíricas. A Resolução do CFP no 01/1999 (CFP, 1999) orientou a amostra de conveniência para análise das relações entre Psicologia e fundamentalismo religioso por consistir em uma normativa da categoria de classe profissional que sofre ofensiva direta de parlamentares de bancadas religiosas. Para tanto se levantou no Portal da Câmara dos Deputados proposições legislativas a partir dos termos de busca "Resolução no 01/1999 do Conselho Federal de Psicologia" e "tratamento de homossexuais", tendo alcançado três proposições apresentadas entre os anos 2011 e 2016.

No que se refere à construção de normativas do sistema conselhos de Psicologia sobre laicidade e fundamentalismo religioso, aproveitou-se a compilação realizada pelo Conselho Regional de Psicologia (CRP) de São Paulo publicada em seu sítio virtual na seção Áreas Temáticas, cujo tema é Diversidade Epistemológica não Hegemônica em Psicologia, Laicidade e Diálogo com Saberes Tradicionais (Diverpsi) ${ }^{2}$. A atualização dos dados foi realizada ao se verificar diretamente o sítio virtual do Conselho Federal de Psicologia (CFP) e o Relatório Preliminar do IX Congresso Nacional da Psicologia, documento de referência para conhecer as deliberações democráticas da categoria sobre atuação do sistema conselhos de Psicologia.

A partir dos documentos de referência levantados tanto por meio do Portal da Câmara dos Deputados quanto aqueles concernentes ao Sistema Conselhos de Psicologia, foram estabelecidas três categorias analíticas a partir das quais é possível discutir a complexidade das relações entre Psicologia, laicidade e fundamentalismo religioso: (1) ofensivas fundamentalistas contra a Psicologia; (2) uso da Psicologia por fundamentalistas religiosos; e (3) compromisso da Psicologia na defesa da laicidade.

${ }^{2}$ O Conselho Regional de Psicologia de São Paulo (CRP/SP) vem organizando Cadernos Temáticos que podem ser acessados na seção "Áreas Temáticas" do sítio virtual. O Caderno Temático "Diversidade Epistemológica não-hegemônica em Psicologia, Laicidade e Diálogo com Saberes Tradicionais" pode ser recuperado por meio do link http://www.crpsp.org.br/diverpsi/. 


\section{Resultados}

O fundamentalismo religioso no contexto brasileiro se relaciona com a Psicologia em pelos menos três dimensões. A primeira é a da ofensiva fundamentalista contra normativas éticas da profissão no cenário parlamentar, na lógica de proposições legislativas que incidem sobre normativa ética da profissão, a saber a Resolução $n^{\circ}$ CFP 01/ 1999 (CFP, 1999). A segunda é a do uso da Psicologia para os propósitos do fundamentalismo religioso. A incidência do viés religioso no seio da própria Psicologia também partilha de premissas fundamentalistas ao propor a anterioridade da convicção de fé sobre discursos científicos e práticas psicológicas, subalternizando os consensos democráticos construídos pela categoria de classe profissional em prol da imposição de irrevogabilidade de preceitos de fé em todas as dimensões da vida social, incluso o exercício profissional. É o caso da pretensa adjetivação cristã para a Psicologia, desvirtuando a identidade profissional. A terceira é a da construção de marcos de referência para a categoria profissional na afirmação da laicidade e do necessário enfrentamento do fundamentalismo religioso no cenário brasileiro contemporâneo.

\section{Ofensivas fundamentalistas contra a Psicologia}

A principal ofensiva contra a Psicologia se refere ao tratamento das homossexualidades, na forma de proposições legislativas que incidem sobre a própria autonomia da categoria de classe profissional na regulação ética da profissão. O Projeto de Decreto Legislativo (PDC) $\mathrm{n}^{\circ}$ 234/2011, de autoria do Deputado Federal João Campos decorreu em variadas audiências públicas antes de seu arquivamento, em 2013. A proposição visava sustar o parágrafo único do artigo segundo da resolução, bem como o seu artigo terceiro, que tratam respectivamente do veto às terapias de reversão da orientação sexual e do impedimento do pronunciamento público por parte de profissionais que tendessem à patologização da homossexualidade. O deputado alega, na justificação da proposição, que "o Conselho Federal de Psicologia, ao restringir o trabalho dos profissionais e o direito da pessoa de receber orientação profissional, por intermédio do questionado ato normativo, extrapolou o seu poder regulamentar". Note-se que o teor argumentativo da proposição é o de que liberdades de profissionais teriam sido cerceadas pela resolução do conselho de classe, não recorrendo à argumentação religiosa, mas sim à retórica legalista.

Em 2016 a ofensiva foi atualizada por meio da proposição do Projeto de Decreto Legislativo $n^{\circ} 539 / 2016$, de autoria do Deputado Federal Pastor Eurico. Enquanto o PDC $n^{\circ} n^{\circ} 234 / 2011$ se propunha a sustar dois parágrafos da Resolução, a saber, a destinada a vedar a manifestação pública de profissionais de Psicologia no sentido de patologizar a homossexualidade e o veto aos tratamentos de reversão da orientação sexual, o PDC n ${ }^{\circ}$ 539/2016 se propõe a sustar o inteiro teor da Resolução, propondo que não haja mais normativa ética e técnica da profissão específica sobre a homossexualidade. $\mathrm{O}$ argumento adotado pelo deputado pastor é o do ultrapassamento das competências do conselho de classe, que teria incidido em censura de profissionais por meio da resolução, alegando que "não pode o Estado estabelecer, a priori, o que pode e o que não pode ser dito pelos indivíduos, muito menos um Conselho de entidade profissional regulamentar" (s.p.). As proposições foram apelidadas pela opinião pública como projetos de "cura gay", e o teor da argumentação adotada já foi objeto de análise por parte de Rios, Silva, Resadori e Vidor (2017), que reafirmaram a autonomia do CFP como autarquia federal na proposição de marcos normativos para o exercício profissional em consonância com o marco constitucional democrático brasileiro. Ainda, o deputado pastor argumenta que

não bastasse tal censura violar o direito fundamental da proteção ao desenvolvimento da ciência, também violou o seu direito de regular a profissão, como já demonstrado acima, pois ultrapassou sua margem em desrespeito a mais um direito fundamental do artigo $5^{\circ}$, II, da CF, que dispositiva "ninguém será obrigado a fazer ou deixar de fazer alguma coisa senão em virtude de lei" (Pastor Eurico, 2016, s.p.)

Ambas as proposições de decretos legislativos adotam a argumentação legalista, remetendo a argumentação para o direito constitucional. Curiosamente a ofensiva contra normativa da Psicologia propõe que interesses científicos estariam sendo cerceados por um mecanismo de censura contra profissionais de Psicologia que viessem a desenvolver pesquisas sobre métodos de tratamento de pessoas homossexuais que 
estivessem em conflito moral com a própria orientação sexual, a chamada egodistonia na terminologia médico psiquiátrica. Apesar da relação direta de ambos os deputados com a Bancada Evangélica, não se adota retórica religiosa nas proposições legislativas, o que leva à consideração do manto cientificista e legalista como estratégia argumentativa dos fundamentalistas religiosos na política.

Ainda, foi apresentado o Projeto de Lei (PL) $n^{\circ} 4931 / 2016$ pelo Deputado Federal Ezequiel Teixeira, também integrante da Bancada Evangélica, que propõe "assegurar o direito à modificação da orientação sexual em atenção à dignidade humana". O PL $\mathrm{n}^{\circ} 4931 / 2016$ propõesugere suspender quaisquer sanções relativas a profissionais que praticassem tratamentos "visando auxiliar a mudança da orientação sexual, deixando o paciente de ser homossexual para ser heterossexual" (s.p.). De acordo com a proposição legislativa,

Art. $1^{\circ}$ Fica facultado ao profissional de saúde mental, atender e aplicar terapias e tratamentos científicos ao paciente diagnosticado com os transtornos psicológicos da orientação sexual egodistônica, transtorno da maturação sexual, transtorno do relacionamento sexual e transtorno do desenvolvimento sexual, visando auxiliar a mudança da orientação sexual, deixando o paciente de ser homossexual para ser heterossexual, desde que corresponda ao seu desejo.

Art. $2^{\circ} \mathrm{O}$ profissional que atuar em atenção ao artigo anterior, não poderá sofrer qualquer sanção pelos órgãos de classe.

$\mathrm{O}$ argumento do Deputado Ezequiel Teixeira vem confirmar a hipótese do manto de cientificismo como estratégia fundamentalista, ao afirmar que "no entanto, visando não entrar, apenas, no campo religioso e para manter o debate no aspecto científico" (s.p.), recupera algumas classificações disponíveis nos manuais diagnósticos da psiquiatria para se referir ao caráter doentio da homossexualidade, que não deixa de explicitar como a concepção que fundamenta o Projeto de Lei: "penso que a homossexualidade causa diversos transtornos psicológicos” (s.p.).
Tais ofensivas fundamentalistas contra a Psicologia adotam manto legalista e cientificista para forjar interesse científico para a garantia da liberdade de mudar a orientação do desejo sexual. Desconsideram que a normativa da Psicologia se fundamenta não apenas no marco político de compromisso da Psicologia com direitos humanos, mas também em consensos científicos sobre a ineficácia das terapias de reversão da orientação sexual, tais como sistematizados no documento produzido pela American Psychological Association denominado Appropriate Therapeutic Responses to Sexual Orientation (American Psychological Association, 2009). Tal documento de referência apresenta como principais resultados da revisão de estudos empíricos de reversão da orientação sexual: a não garantia de mudança da orientação sexual por meio de técnicas psicoterapêuticas; o agravamento do sofrimento psíquico decorrente de tais práticas; e a ideação religiosa como principal justificativa para as demandas por terapias de reversão. Sinaliza, ainda, para a importância do manejo clínico psicoterapêutico entre as convicções de fé e a necessidade de manutenção de posição ética pela não patologização da homossexualidade. Isso leva à consideração da importância do reconhecimento e respeito às convicções de fé das pessoas, o que não se confunde com ser conivente com a patologização e orientação dos esforços terapêuticos na lógica da reversão.

\section{O uso da Psicologia por fundamentalistas religiosos}

A problemática se complexifica quando se pode evidenciar que durante as audiências públicas relacionadas à matéria, especificamente em relação ao PDC $n^{\circ}$ 234/2011, a Psicologia tem sido acionada para defender as proposições legislativas oriundas da incidência do discurso religioso de viés fundamentalista na política nacional. Isso leva à necessidade de consideração da segunda forma de associar a Psicologia à violação da laicidade: o uso da Psicologia para os propósitos fundamentalistas. Durante as audiências públicas realizadas para debater o PDC n ${ }^{\circ}$ 234/2011, uma profissional de Psicologia que se auto-intitulaautointitula "psicóloga cristã" 3 participou na defesa do projeto, assim como o pastor Silas Malafaia fez questão de explicitar que tem formação em Psicologia em

${ }^{3}$ Trata-se do caso da missionária Marisa Lobo, amplamente difundido na mídia nacional. A mesma tem participado de debates públicos sobre drogas e gênero, com ênfase em narrativas moralistas e familistas e patologização das homossexualidades e usuários de drogas. 
suas argumentações favoráveis à proposição legislativa. Isso significa que mesmo nas ofensivas contra a Psicologia que tem sido desencadeadas por meio de projetos legislativos fundamentalistas, a Psicologia tem sido usada como argumento de autoridade para questionar a própria autonomia da Psicologia como profissão. Pode-se compreender que o manto de cientificidade é a principal estratégia argumentativa adotada por fundamentalistas religiosos nas disputas políticas, inclusive na ofensiva contra a Psicologia, de modo a requerer compreensão do fundamentalismo religioso como projeto político antidemocrático que não se assenta na afirmação literal do texto sagrado, mas na autoatribuição de superioridade moral à posição religiosa. No entanto, a posição moral religiosa se apresenta pretensamente em linguagem científica a fim de conquistar credibilidade nas disputas políticas em uma era secular.

Vale destacar a inoperância do sistema conselhos de Psicologia na coibição de tais práticas, pois a representação ética contra profissional de Psicologia que explicitamente viola preceitos do código de ética profissional e da Resolução CFP n ${ }^{\circ}$ 01/99 por meio de site e comunicações públicas não decorreu na alteração do teor público de seus pronunciamentos. . Além de narrativas publicadas na internet e/ou materiais impressos, Marisa Lobo inclusive usou a polêmica pública em torno da representação ética sofrida como motor de campanha política para candidatura à câmara legislativa do seu estado de referência, em $2014^{4}$.

O CRP do Paraná emitiu Nota Técnica sobre a confissão da fé e o exercício profissional em 2015, afirmando que

A(O) Psicóloga(o), assim como todo ser humano, pode ou não ter uma identificação religiosa, mística e/ou espiritual. Entretanto, trata-se aqui de esclarecer a relação da expressão da identidade religiosa, sobre a qual não há restrições, com a atividade profissional, essa sim regulamentada pelo código de ética da profissão, e evitar possí- veis conflitos com este. De tal forma que reafirma: a nomenclatura na identificação da(o) profissional deve referir-se à atuação deste e não a aspectos de foro íntimo, como sua confissão de fé (s.p.). ${ }^{5}$

Tal associação entre a fé e o exercício profissional não deve ser entendida como caso isolado. Em 2017, o CRP do Rio de Janeiro e o CFP emitiram posicionamentos públicos sobre as ofertas de formação em "Psicologia Cristã" que tem se apresentado no país. Ambos os conselhos afirmam que a "Psicologia Cristã” não é uma das doze especialidades reconhecidas pela categoria de classe, remetendo a formação em Psicologia para parâmetros normativos estabelecidos por legislação específica e afirmando a laicidade da profissão ${ }^{6}$.

\section{A Psicologia na defesa da laicidade}

A terceira forma de compreender o modo como a Psicologia estabelece relação com o fundamentalismo religioso no Brasil é a proposição de marcos de referência, no âmbito do sistema conselhos de Psicologia, para afirmação da defesa da laicidade e necessidade de recusar o fundamentalismo religioso. A este respeito, além de compreender que o Código de Ética Profissional e as Resoluções CFP n ${ }^{\circ} 01 / 1999$ (CFP, 1999) e Resolução CFP nº 018/2002 (CFP, 2002), que respectivamente versam sobre coibição de discriminação por orientação sexual e cor, são marcos relevantes de afirmação da laicidade por meio do reconhecimento e valorização da diversidade moral, cultural, social e subjetiva, o sistema conselhos de Psicologia tem produzido outras referências mais explicitamente afirmativas na defesa da laicidade.

É importante notar que a emergência histórica de marcos éticos na profissão que explicitam a defesa da laicidade e a recusa do fundamentalismo religioso passam a integrar documentos de referência para a categoria profissional em 2013, o que leva à constatação de

\footnotetext{
${ }^{4}$ Marisa Lobo foi candidata a Deputada Federal pelo Partido Social Cristão no Paraná em 2014, tendo registrado candidatura como "Psicóloga Cristã Marisa Lobo", de acordo com as informações públicas disponíveis em https://www.eleicoes2014.com.br/psicologa-crista-marisa-lobo/.

${ }^{5}$ Conselho Regional de Psicologia do Paraná, 2015, emite Nota Técnica sobre confissão de fé e exercício profissional. Recuperado de http://portal.crppr.org.br/noticia/nota-tecnica-sobre-a-confissao-de-fe-e-a-atuacao-profissional.

${ }^{6}$ Nota de posicionamento do Conselho Regional de PsicologiaCRP sobre titulação em "Psicologia Cristã". Recuperado de https://www. facebook.com/crprj/photos/a.237085729713281.60582.236430 666445454/1259904200764757/?type=3\&theater.

Nota de posicionamento do CFP sobre formação em "Psicologia Cristã". Recuperado de http://site.cfp.org.br/formacao-em-psicologia-crista-comunicado-do-cfp/
} 
que decorrem dos ataques sofridos pela Psicologia no Congresso Nacional por parte da Bancada Evangélica.

Diante de tais ofensivas à própria autonomia da classe profissional, em 2013 foram deliberadas quatro moções durante o VIII Congresso Nacional de Psicologia (CNP, 2013), que consiste na instância deliberativa de consensos democráticos da categoria profissional. A $11^{\text {a }}$ Moção repudia as terapias de reversão da orientação sexual, assim como a $12^{\mathrm{a}}$ Moção repudia explicitamente o PDC no ${ }^{\circ}$ 234/2011. A 14 ${ }^{a}$ Moção consiste em apoio à inclusão do diálogo com epistemologias não hegemônicas e os saberes tradicionais nos ambientes de formação e pesquisa, complexificando a reflexão da categoria profissional sobre a necessidade de reconhecimento de epistemologias não científicas que tangenciam valores tradicionais, na perspectiva da integralidade da atenção à saúde e das práticas integrativas e complementares no âmbito do Sistema Único de Saúde. Esta moção é relevante pois denota a abertura da Psicologia ao reconhecimento e valorização de práticas sociais e culturais que tangenciam crenças religiosas ou práticas de espiritualidade, sem discriminação a tais formas de compreender e intervir sobre os processos de sofrimento, adoecimento e cuidado em saúde, afirmando o caráter democrático do compromisso social da Psicologia.

No entanto, no mesmo VIII Congresso Nacional da Psicologia, foi também aprovada a $15^{\mathrm{a}}$ Moção, que repudia ações reducionistas que atentem contra a liberdade de crença e de consciência, afirmando a laicidade como valor a ser defendido contra

qualquer tentativa fundamentalista de quaisquer grupos, sejam eles religiosos, científicos ou de quaisquer naturezas que procurem cooptar consciências, naturalizar as desigualdades, recusar-se ao diálogo que desconsidere a construção histórica da realidade e que, portanto, queiram impor sobre a sociedade quaisquer formas de reducionismo dogmático proposto por projetos, sejam de lei ou de outra natureza, regulamentações ou quaisquer formas de imposição totalitárias que atentem sobre as liberdades instituídas e o Estado de Direito. (Congresso Nacional de Psicologia, 2013, pag. 65-66).

Vale destacar que em 2013, ainda, o Grupo de Trabalho Laicidade e Psicologia, que envolve conselheiros de diferentes Conselhos Regionais e CFP, teve aprovada na APAF do sistema conselhos de Psicologia a Nota Técnica Laicidade e Psicologia - Posicionamento do Sistema Conselhos de Psicologia para a questão da Psicologia, religião e espiritualidade (GT Nacional Laicidade e Psicologia, 2013 apud Conselho Regional de Psicologia/SP, 2014). Tal documento de referência afirma que a Psicologia não se funda em verdade dogmática religiosa, o que não significa que profissionais de Psicologia não possam ter religião. A Psicologia reconhece que no conjunto da sociedade as pessoas apresentam diferentes vinculações a doutrinas e instituições religiosas, e também reconhece que há pessoas que não expressam fé em nenhuma religião ou mesmo afirmam que não acreditam na existência de Deus, o que não significa que estas últimas não estejam comprometidas com o justo e com a busca por melhores condições de vida em sociedade. A Psicologia reconhece que a espiritualidade é uma experiência subjetiva fundamental à condição humana, se referindo à busca de sentido sobre as origens e o destino da humanidade, condição básica de produção de sentido sobre aquilo para o qual não temos respostas passíveis de verificação. Toda religião tem uma dimensão de espiritualidade, mas a espiritualidade como condição humana não requer vinculação às religiões, sendo a espiritualidade também uma dimensão subjetiva de pessoas que não tem religiosidade. Afirma, ainda, que a Psicologia como ciência não se baseia em verdades transcendentais, mas reconhece que nem todo o conjunto da sociedade organiza suas práticas com base na ciência. Afirma a importância dos saberes tradicionais, que podem inclusive associar práticas de cura a verdades religiosas. Saberes tradicionais são práticas de cura pré-científicas que inclusive parte da ciência se dedica a compreender os fundamentos de sua eficácia pois mesmo antes da emergência das ciências na Modernidade os grupos sociais organizaram seus conhecimentos e práticas de modo a cuidar de seus povos. Por fim, afirma a recusa "qualquer tentativa fundamentalista de imposição de dogma religioso, seja ele qual for, sobre o Estado, a Ciência e a profissão" (GT Nacional Laicidade e Psicologia, 2013 apud CRP/SP, 2014).

Em 2014, ano eleitoral, foi apresentada a "Carta dos Conselhos Regionais de Psicologia à População Brasileira: Psicologia, laicidade e discurso religioso nas eleições" (CRP/SP, 2014). O documento afirma que para a manutenção democrática do debate eleito- 
ral partidos deveriam apresentar propostas sem apelo a argumentos que promovem ideologias fundamentalistas, comprometendo a dignidade de diversos grupos sociais a partir de polarizações morais em torno da agenda de direitos humanos.

O IX CNP, realizado em 2016, aprovou ainda proposta de construção de Política Nacional de Psicologia e Laicidade,

priorizando o compromisso da atuação do (a) psicólogo (a) com base na laicidade, reconhecendo e respeitando a pluralidade de manifestações religiosas e repudiando as construções ideológicas que ferem o Código de Ética Profissional e à Resolução CFP no 001/1999, que estabelece normas de atuação para os psicólogos em relação à questão da Orientação Sexual, e Resolução CFP $\mathrm{n}^{\circ} 018 / 2002$, que estabelece normas de atuação para os psicólogos em relação a preconceito e discriminação racial (CNP, 2016, pag. 27).

A argumentação que segue a proposição de uma Política Nacional de Psicologia e Laicidade orienta parâmetros a partir dos quais se deveriam guiar as reflexões e deliberações a serem construídas pela categoria de classe. A menção às Resoluções CFP ${ }^{\circ}$ 01/1999 (CFP, 1999) e $\mathrm{n}^{\circ} 018 / 2002$ (CFP, 2002), que tratam da homossexualidade e do racismo, levam ao entendimento de que a consideração das interfaces entre Psicologia e religiosidade não deveriam, por um lado, decorrer em patologização ou violação da dignidade de homossexuais, e por outro, deveriam reconhecer especificidades culturais da população negra, possivelmente incluindo a questão das religiosidades de matriz africanas sem discriminação. Ainda, pode-se compreender que o repúdio a construções ideológicas que feririam o código de ética profissional remete ao posicionamento da categoria de classe pela reafirmação do reconhecimento da diversidade moral, cultural e religiosa da sociedade brasileira e contra o fundamentalismo religioso.

\section{Concluindo um esforço de sistematização: a Psicologia ontem, hoje e amanhã.}

É importante considerar que a incidência do discurso religioso na política nacional tem se revelado uma ofensiva fundamentalista antidemocrática e usurpadora da agenda de direitos humanos para fins de polarização moral e acirramento das desigualdades com prejuízo para grupos sociais historicamente marginalizados, tais como mulheres, minorias sexuais e população negra.

A Psicologia como ciência e como profissão conta em sua história com marco necessário de afirmação de compromisso com a ética democrática e com a defesa e promoção dos direitos humanos, tendo em momento histórico anterior se demonstrado conivente com forças conservadoras hegemônicas de manutenção de desigualdades sociais e mesmo de autoritarismo estatal. Torna-se extremamente importante primar pela construção de uma identidade profissional consciente de sua história de modo a implicar o compromisso da categoria profissional com a defesa do Estado de Direito democrático.

A laicidade da Psicologia deve ser afirmada como pilar de sua legitimidade científica, bem como de seu compromisso histórico com a democracia e participação nas políticas públicas e estratégias de garantia de direitos sociais, econômicos, políticos e culturais. Dado o caráter paradoxal da relação entre Psicologia, laicidade e fundamentalismo religioso na contemporaneidade, faz-se necessário ampliar os debates sobre ética profissional, primando pelo reconhecimento da diversidade subjetiva, moral, social e cultural como valor na sociedade brasileira.

Os esforços para aproximação entre o sistema conselhos de Psicologia, por um lado, e a Psicologia acadêmica, por outro, é fundamental para que a formação em Psicologia esteja comprometida com a função histórica e social da Psicologia como ciência e como profissão na luta pela construção de uma sociedade democrática. Faz-se necessário acompanhar reflexões críticas sobre o atual cenário político brasileiro a partir da consideração do lugar da Psicologia neste processo, de modo a promover mudança em representações e discursos teóricos datados que não necessariamente correspondem aos desafios éticos para o exercício profissional na contemporaneidade.

Espera-se que profissionais de Psicologia inseridos nos mais variados campos de atuação profissional atentem para a importância da defesa da laicidade, da ética democrática e da recusa a toda forma de discriminação e intolerância, de modo a revisar historicamente a função da Psicologia no agenciamento de práticas e discursos de normalização, primando pelo reconhecimento dos direitos humanos e garantia de direitos sociais, econômicos e políticos fundamentais à democracia. 
Este estudo exploratório permite sinalizar algumas direções de reflexões que podem ser importantes para o processo de construção de uma Política Nacional de Laicidade e Psicologia. Um dos caminhos a serem trilhados é o da revisão sistemática e crítica do campo da Psicologia da Religião, a fim de verificar se há tendenciosidade religiosa na produção de conhecimento em Psicologia. A inexistência de estudos que tematizem a laicidade como conceito estruturante da reflexão sobre as relações entre Psicologia e religiosidade e/ou espiritualidade pode ser um sinal de não garantia deste princípio tão caro à proteção das diversidades.

Outro caminho a ser percorrido é o da reflexão crítica sobre como reconhecer saberes tradicionais e epistemologias não hegemônicas mantendo a neutralidade laica da Psicologia. Pode parecer simples a reivindicação da aproximação da Psicologia aos saberes tradicionais tais como oriundos de comunidades indígenas e quilombolas ou dos povos de santo, mas a questão ética deve ser a de como não estabelecer laços de associação da fé ao exercício profissional, assim como deve ser vedado em relação à fé cristã afirmada majoritária em nosso país.

Uma das direções interessantes para avançar no compromisso da Psicologia com a ética democrática, a laicidade e contra fundamentalismos religiosos seria a retomada do Movimento Estratégico do Estado Laico $^{7}$. Tal iniciativa decorreu de articulação do próprio Conselho Federal de Psicologia com a sociedade civil organizada para a defesa da laicidade do Estado diante das ameaças do fundamentalismo religioso à democracia. O diálogo com diferentes movimentos sociais de defesa dos direitos humanos e também com comunidades de fé de diferentes matizes religiosos é um caminho interessante para tecer diretrizes éticas e técnicas condizentes com a complexidade e diversidade moral, cultural e religiosa da sociedade brasileira.

\section{Referências}

American Psychological Association - APA. (2009). Report of the American Psychological Association Task Force on Appropriate Therapeutic Responses to Sexual Orientation. Washington, D.C.: o autor. Recuperado de http:// www. apa.org/pi/lgbc/publications/therapeutic-resp.html

Armstrong, K. (2016). Campos de sangue: religião e a história da violência. São Paulo, SP: Companhia das Letras.

Armstrong, K. (2009). Em nome de Deus: o fundamentalismo no judaísmo, no cristianismo e no islamismo. São Paulo, SP: Companhia das Letras.

Bárbara, I. S. M. S.; Cunha, F. L., \& Bicalho, P. P. G. (2017). Escola sem partido: visibilizando racionalidades, analisando governamentalidades. In Frigotto, G. (Org.), Escola "sem"Partido: esfinge que ameaça a educação e a sociedade brasileira (pp. 105-120). Rio de Janeiro, RJ: LPP/UERJ.

Boff, L. (2002). Fundamentalismo: a globalização e o futuro da humanidade. Rio de Janeiro, RJ: Sextante.

Congresso Nacional da Psicologia - CNP. (2013). Cadernos de deliberação do VIII CNP - Psicologia, Ética e Cidadania: práticas profissionais a serviço da garantia de direitos. Recuperado de: http://site.cfp.org.br/wp-content/ uploads/2013/08/MinutaCadernodelibera\%C3\%A7oes14.08.pdf

Congresso Nacional da Psicologia - CNP. (2016). Cadernos de deliberação do IX CNP - Psicologia no cotidiano por uma sociedade mais democrática e igualitária (versão preliminar). Recuperado de http://9cnp.cfp.org.br/ wp-content/uploads/sites/20/2016/02/CFP_CadCNP_Deliberacoes_WEB.pdf

Conselho Federal de Psicologia - CFP. (1999). Resolução CFP No 01/99, de 22 de março de 1999. Estabelece normas para a atuação dos psicólogos em relação à questão da orientação sexual. Brasília, DF: o autor. Recuperado de https://site.cfp.org.br/wp-content/uploads/1999/03/resolucao1999_1.pdf

Conselho Federal de Psicologia - CFP. (2005). Resolução CFP No 010/2005, de 21 de julho de 2004. Aprova o Código de Ética Profissional do Psicólogo. Brasília, DF: o autor. Recuperado de https://site.cfp.org.br/wpcontent/uploads/2005/07/resolucao2005_10.pdf

\footnotetext{
${ }^{7}$ O Movimento Estratégico pelo Estado Laico dispõe de um sítio virtual onde foram publicados alguns passos decorrentes desta articulação política impulsionada pelo CFP, pela Associação Brasileira de Lésbicas, Gays, Bissexuais, Travestis e Transexuais (ABGLT), Articulação de Mulheres Brasileiras (AMB) e Plataforma DHESCA. Recuperado de http://www.meel.org.br/
} 
Conselho Federal de Psicologia - CFP. (2002). Resolução CFP No 018/2002, de 19 de dezembro de 2002. Estabelece normas para a atuação dos psicólogos em relação ao preconceito e à discriminação racial. Brasílai, DF: o autor. Recuperado de https://site.cfp.org.br/wpcontent/uploads/2002/12/resolucao2002_18.PDF

Conselho Regional de Psicologia de São Paulo - CRP/SP. (2014). Psicologia, laicidade, espiritualidade, religião e os saberes tradicionais: referências básicas para a atuação profissional. São Paulo, SP: o autor.

Cunha, C. V., Lopes, P. V. L., \& Lui, J. (2017). Religião e política: medos sociais, extremismo religioso e as eleições de 2014. Rio de Janeiro, RJ: Fundação Heinrich Böll.

Demier, F. (2016). O barulho dos inocentes: a revolta dos “homens de bem”. In Demier, F., \& Hoeveler, R. (Orgs.), A onda conservadora: ensaios sobre os atuais tempos sombrios no Brasil (pp. 9-24). Rio de Janeiro: Mauad.

Facchini, R., \& Sívori, H. (2017). Conservadorismo, direitos, moralidades e violência: situando um conjunto de reflexões a partir da Antropologia. Cadernos Pagu, (50), e175000. https://doi.org/10.1590/18094449201700500000

Frigotto, G. (2017). A gênese das teses do Escola sem Partido: esfinge e ovo da serpente que ameaçam a sociedade e a educação. In Frigotto, G. (Org.), Escola "sem" partido: esfinge que ameaça a educação e a sociedade brasileira (pp. 17-34). Rio de Janeiro, RJ: LPP/UERJ.

Gesser, M. (2013). Políticas públicas e direitos humanos: desafios à atuação do Psicólogo. Psicologia Ciência e Profissão, 33(num. Especial), 66-77. Recuperado de http://www.scielo.br/scielo.php?script=sci_abstract\&pi$\mathrm{d}=\mathrm{S} 1414-98932013000500004 \& \operatorname{lng}=\mathrm{en} \& \mathrm{nrm}=\mathrm{iso} \& \operatorname{lng}=\mathrm{en}$

Lionço, T. (2015). Laicidade, gênero, sexualidade e fundamentalismo cristão no Brasil. In Plataforma DHESCA. Relatorias em direitos humanos 2012-2014 (pp. 21-33). Curitiba, PR: Terra de Direitos.

Natividade, M. (2016). Margens da política: estado, direitos sexuais e religiões. Rio de Janeiro, RJ: Garamond.

Natividade, M., \& Oliveira, L. (2013). As novas guerras sexuais: diferença, poder religioso e identidades LGBT no Brasil. Rio de Janeiro, RJ: Garamond.

Natividade, M., \& Oliveira, L. (2009). Sexualidades ameaçadoras: religião e homofobia(s) em discursos evangélicos conservadores. Sexualidad, Salud y Sociedad, (2), 121-161. Recuperado de http://www.e-publicacoes.uerj.br/ index.php/SexualidadSaludySociedad/article/view/32/445

Nussbaum, M. (2008). Liberty of conscience: in defense of America's tradition of religious equality. New York, NY: Basic Books.

Nussbaum, M. (2012). The new religious intolerance : overcoming the politics of fear in an anxious age. Massachusetts: The Belknap Press of Harvard University Press.

Projeto de Decreto Legislativo n. 234 de 02 de Junho de 2011. Susta a aplicação do parágrafo único do art. $3^{\circ}$ e o art. $4^{\circ}$, da Resolução do Conselho Federal de Psicologia no 1/99 de 23 de Março de 1999, que estabelece normas de atuação para os psicólogos em relação à questão da orientação sexual. Recuperado de http://www.camara.gov. $\mathrm{br} /$ proposicoesWeb/fichadetramitacao?idProposicao $=505415$

Projeto de Decreto Legislativo n. 539 de 06 de Outubro de 2016. Susta os efeitos da Resolução no 01, de 22 de março de 1999, editada pelo Conselho Federal de Psicologia - CFP. Recuperado de http://www.camara.gov.br/proposicoesWeb/fichadetramitacao?idProposicao $=2113432$

Projeto de Lei n. 4931 de 06 de Abril de 2016. Dispõe sobre o direito à modificação da orientação sexual em atenção a Dignidade Humana. Recuperado de http://www.camara.gov.br/proposicoesWeb/fichadetramitacao?idProposicao $=2081600$

Rios, R. R., Silva, R., Resadori, A. H., \& Vidor, D. M. (2017). Laicidade e Conselho Federal de Psicologia: dinâmica institucional e profissional em perspectiva jurídica. Psicologia: Ciência e Profissão, 37(1), 159-175. https://doi. org/10.1590/1982-3703002612016

Rorty, R. (2010). Uma ética laica. São Paulo, SP: Martins Fontes.

Rosato, C. M. (2011). Psicologia e direitos humanos: cursos e percursos comuns. Psicologia Revista, 20(1), 11-27. Recuperado de https://revistas.pucsp.br/index.php/psicorevista/article/view/6790

Rose, N. (2011). Inventando nossos selfs: psicologia, poder e subjetividade. Rio de Janeiro, RJ: Vozes.

Santos, B. S. (2013b). Direitos humanos, democracia e desenvolvimento. In Santos, B. S., \& Chauí, M., Direitos humanos, democracia e desenvolvimento (pp. 31-133). São Paulo, SP: Cortez. 
Santos, B. S. (2013a). Se Deus fosse um ativista de direitos humanos. São Paulo, SP: Cortez.

Scarparo, H. B. K., Torres, S., \& Ecker, D. D. (2014). Psicologia e ditadura civil-militar: reflexões sobre práticas psicológicas frente às violências de estado. Revista EPOS, 5(1), 57-78. Recuperado de http://pepsic.bvsalud.org/scielo. php?script=sci_arttext\&pid=S2178-700X2014000100004

Schlegel, J-L. (2009). A lei de Deus contra a liberdade dos homens. São Paulo, SP: Martins Fontes.

Schwartzman, S. (2008). Ciência, universidade e ideologia: a política do conhecimento. Rio de Janeiro, RJ: Centro Edelstein.

Sen, A. (2010). Elementos de uma teoria de direitos humanos. in Diniz, D., \& Santos, W. (Orgs.), Deficiência e discriminação (pp. 19-72). Brasília, DF: Editora UnB.

Sen, A. (2011). A ideia de justiça. São Paulo, SP: Companhia das Letras.

Strauss, A., \& Corbin, J. (2008). Pesquisa qualitativa: técnicas e procedimentos para o desenvolvimento de teoria fundamentada. São Paulo, SP: Artmed.

Vital, C., \& Lopes, P.V. L. (2013). Religião e Política: uma análise da atuação de parlamentares evangélicos sobre direitos das mulheres e de LGBTs no Brasil. Rio de Janeiro, RJ: Fundação Heinrich Böll.

\section{Tatiana Lionço}

Professora Adjunta do Departamento de Psicologia Escolar e do Desenvolvimento do Instituto de Psicologia da Universidade de Brasília, Brasília -DF. Brasil.

E-mail: tlionco@gmail.com

Endereço para envio de correspondência:

Departamento de Psicologia Escolar e do Desenvolvimento, Campus Darcy Ribeiro - ICC Sul, Instituto de Psicologia. CEP: 72.910-000.

Brasília - DF. Brasil.

Recebido 30/06/2017

Reformulação 01/10/2017

Aprovado 02/10/2017

Received 06/30/2017

Reformulated 10/01/2017

Approved 10/02/2017

Recebido 30/06/2017

Reformulado 01/10/2017

Aceptado 02/10/2017

Como citar: Lionço, T. (2017). Psicologia, democracia e laicidade em tempos de fundamentalismo religioso no Brasil. Psicologia: Ciência e Profissão, 37(n. spe), 208-223. https://doi.org/10.1590/1982-3703160002017

How to cite: Lionço, T. (2017). Psychology, democracy and laicity in times of religious fundamentalism in Brazil. Psicologia: Ciência e Profissão, 37(n. spe), 208-223. https:// doi.org/10.1590/1982-3703160002017

Cómo citar: Lionço, T. (2017). Psicologia, democracia y laicidad en los tiempos de fundamentalismo religioso no Brasil. Psicologia: Ciência e Profissão, 37((n. spe), 208-223. https://doi.org/10.1590/1982-3703160002017 